\title{
Asymmetric Amine-Intercepted Nazarov Cyclization
}

\author{
Francis Dhoro ${ }^{\mathrm{a}}$, Tor E. Kristensen ${ }^{\mathrm{a}}$, Vegar Stockmann ${ }^{\mathrm{a}}$, Glenn P. A. Yap ${ }^{\mathrm{b}}$, and Marcus A. \\ Tius ${ }^{\mathrm{a}}$ \\ a Department of Chemistry, 2545 The Mall, University of Hawaii, Honolulu, Hawaii 96822, tius@ hawaii.edu \\ b Department of Chemistry \& Biochemistry, University of Delaware, Newark, Delaware 19716
}

The Nazarov cyclization ${ }^{1}$ is an efficient process for the construction of cyclopentenone rings from simple acyclic precursors. One of the variants ${ }^{2}$ of the Nazarov reaction that we recently described is the cascade isomerization-cyclization-trapping process shown in Scheme 1. Addition of propargyllithium 1 to morpholino enamide $\mathbf{2}$ led to propargyl vinyl ketone $\mathbf{3}$. Exposure of $\mathbf{3}$ to dry activated silica gel that had been thoroughly mixed with 1.2 equiv of cyclohexylamine gave $\alpha$-aminocyclopentenone 4 in $65 \%$ yield. Amine-promoted isomerization of $\mathbf{3}$ led to an allenyl vinyl ketone that underwent cyclization in the presence of the weakly acidic silica gel. Trapping of the intermediate carbocation by the amine, followed by tautomerization and double bond migration led to the observed product.

We hypothesized that the process of Scheme 1 could be carried out with the camphor-derived chiral auxiliary ${ }^{3}$ that we developed in place of the propargylic methoxyl. Addition of propargyllithium 5 to morpholino enamide 2 led to ketone $\mathbf{6}$ (86\% yield; Scheme 2) in a highly stereoselective reaction ( $c a .50 / 1$ in all cases). ${ }^{4}$ Vigorous agitation of 6 for 45 min with dry activated Florisil ( $c a .6 \mathrm{~g} / \mathrm{mmol}$ ketone) that had been treated with 10 equiv of phenethylamine gave amino ketone 9 in $67 \%$ yield from $\mathbf{6}$ as a single diastereomer. The reaction also took place in the presence of silica gel, alumina (neutral, acidic or basic) and in solution, but the yield was lower (40-53\%). Thorough agitation of the reaction mixture was critical.

The interrupted Nazarov reaction has been developed primarily by West and coworkers, as a cascade process for the formation of one or more carbon-carbon ${ }^{5 a-d}$ or carbon-heteroatom $5 \mathrm{e}-$ $\mathrm{f}$ bonds subsequent to cyclization. To the best of our knowledge, the present work represents the first example of an asymmetric interrupted Nazarov cyclization process. Table 1 summarizes the results of a series of examples utilizing ketones 6, 10 and 11 and a series of primary, secondary, cyclic and acyclic amines. Yields of aminocyclopentenones varied from $55 \%$ to $75 \%$. In none of the reactions was any hydrolytic cleavage of the chiral auxiliary observed, testifying to the mildness of the reaction conditions, $\beta$-Phenylcinnamate-derived ketone 12 was not a suitable substrate for the reaction, and led in all cases to complex mixtures of intensely colored decomposition products.

The absolute stereochemistry of the aminocyclopentenone products was determined in the case of 20 through X-ray crystallographic analysis of the derived picrate salt (Figure 1). ${ }^{6}$ The absolute configuration of the ring carbon atoms was determined to be $4 R, 5 S$. The absolute stereochemistry of all other products was assigned by analogy to $\mathbf{2 0}$.

The success of the bimolecular asymmetric interrupted Nazarov cyclizations prompted us to investigate an intramolecular reaction. The amine nucleophile could be located at either the 
$\beta$ or the $\beta$ enone carbon atom through a suitable tether. For our first example we opted to prepare aniline 25 (Scheme 3).

Amide 25 was prepared in three steps according to known procedures. ${ }^{7}$ Nucleophilic addition of 5 to $\mathbf{2 5}$ led cleanly to 26. Exposure of this sensitive aminoketone to activated Florisil (ca. 6 $\mathrm{g} / \mathrm{mmol}$ ketone) and 10 equiv triethylamine in the absence of solvent and with vigorous agitation gave indoline $\mathbf{2 7}$ in $50 \%$ overall yield from $\mathbf{2 5}$. The stereochemistry that is shown 8 reflects the preferred sense of conrotatory ring closure followed by intramolecular trapping of the intermediate carbocation (cf. 8, Scheme 2). It is interesting to note that due to the constraints of the intramolecular attack, the $\alpha$ carbon atom in $\mathbf{2 7}$ has the opposite stereochemistry as for products in which the carbocation is trapped in a bimolecular process.

In conclusion we have demonstrated the first asymmetric version of the amine interrupted Nazarov cylization process. This reaction furnishes diastereomericalry pure products. The success of the whole process relies on the ease with which allenyl vinyl ketones undergo the Nazarov cyclization in the presence of even the weakest acid catalysts, $, 4,9$ the tolerance of the system to acid labile functional groups and the isomerization of the propargyl vinyl ketones which may result in formation of single axial isomers of the intermediate allenyl ketones. This tandem process is likely to have utility in total synthesis. ${ }^{10}$

\section{Supplementary Material}

Refer to Web version on PubMed Central for supplementary material.

\section{Acknowledgements}

Acknowledgment is made to the Department of Defense Breast Cancer Research Program (DAMD17-03-1-0685) and to the National Institutes of Health (GM57873) for generous support.

\section{References}

1. (a) Tius MA. Acc Chem Res 2003;36:284-290. [PubMed: 12693926]For reviews of the Nazarov reaction see: (b)HabermasKLDenmarkSJonesTKPaquetteLAOrganic Reactions45John Wiley \& Sons, Inc.New York19941158 (c) Harmata M. Chemtracts 2004;17:416-435. (d) Frontier AJ, Collison C. Tetrahedron 2005;61:7577-7606. (e) Pellissier H. Tetrahedron 2005;61:6479-6517. (f) Tius MA. Eur J Org Chem 2005:2193-2206.

2. Dhoro F, Tius MA. J Am Chem Soc 2005;127:12472-12473. [PubMed: 16144378]

3. Harrington PE, Murai T, Chu C, Tius MA. J Am Chem Soc 2002;124:10091-10100. [PubMed: $12188673]$ (b) The chiral auxiliary was prepared according to a modified literature procedure (see supporting information).

4. The crude product was purified by rapid chromatography on silica gel. Long contact times with silica gel led to the formation of cyclic material. See: (a) Forest J, Bee C, Cordaro F, Tius MA. Org Lett 2003;5:4069-4072. [PubMed: 14572251] (b) Uhrich EA, Batson WA, Tius MA. Synthesis 2006:2139-2142.

5. (a) Bender JA, Arif AM, West FG. J Am Chem Soc 1999;121:7443-7444. (b) Browder CC, Marmsäter FP, West FG. Org Lett 2001;3:3033-3035. [PubMed: 11554836] (c) Yungai A, West FG. Tetrahedron Lett 2004;45:5445-5448. (d) Bender JA, Blize AE, Browder CC, Giese S, West FG. J Org Chem 1998;63:2430-2431. [PubMed: 11672099] (e) Rostami A, Wang Y, Arif AM, McDonald R, West FG. Org Lett 2007;9:703-706. [PubMed: 17256871] (f) White TD, West FG. Tetrahedron Lett 2005;46:5629-5632.

6. Mariella PR, Gruber JM, Elder JWS. J Org Chem 1961;26:3217-3221.

7. Li H, Yang J, Porter NA. Photochem Photobiol A Chem 2005;169:289-297.

8 . The methyl protons in 27 showed a positive nOe with the benzylic proton.

9. Tius MA, Busch-Petersen J, Yamashita M. Tetrahedron Lett 1998;39:4219-4222. 
10. The TIPS group and chiral auxiliary are easily cleaved from the products. Exposure of 23 to tetra- $n$ butylammonium fluoride in THF led to rapid cleavage of the TIPS group (28, $92 \%$ yield). Subsequent exposure of the product to chlorotrimethylsilane in methanol at $0{ }^{\circ} \mathrm{C}$ led to cleavage of the chiral auxiliary $(29,93 \%$ yield). See the S.I. for details. 

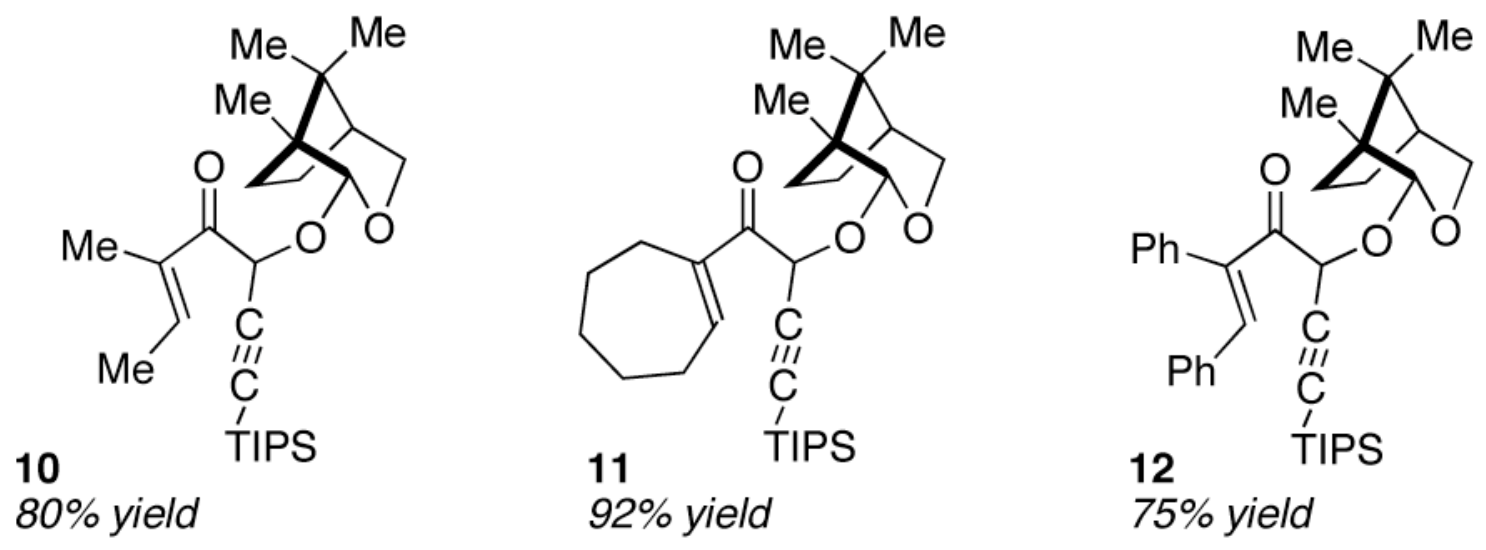

Figure 1.

Propargyl vinyl ketones. ${ }^{\mathrm{a}}$

${ }^{\text {a }}$ Yields refer to the addition of $\mathbf{5}$ to the appropriate morpholino enamide. 

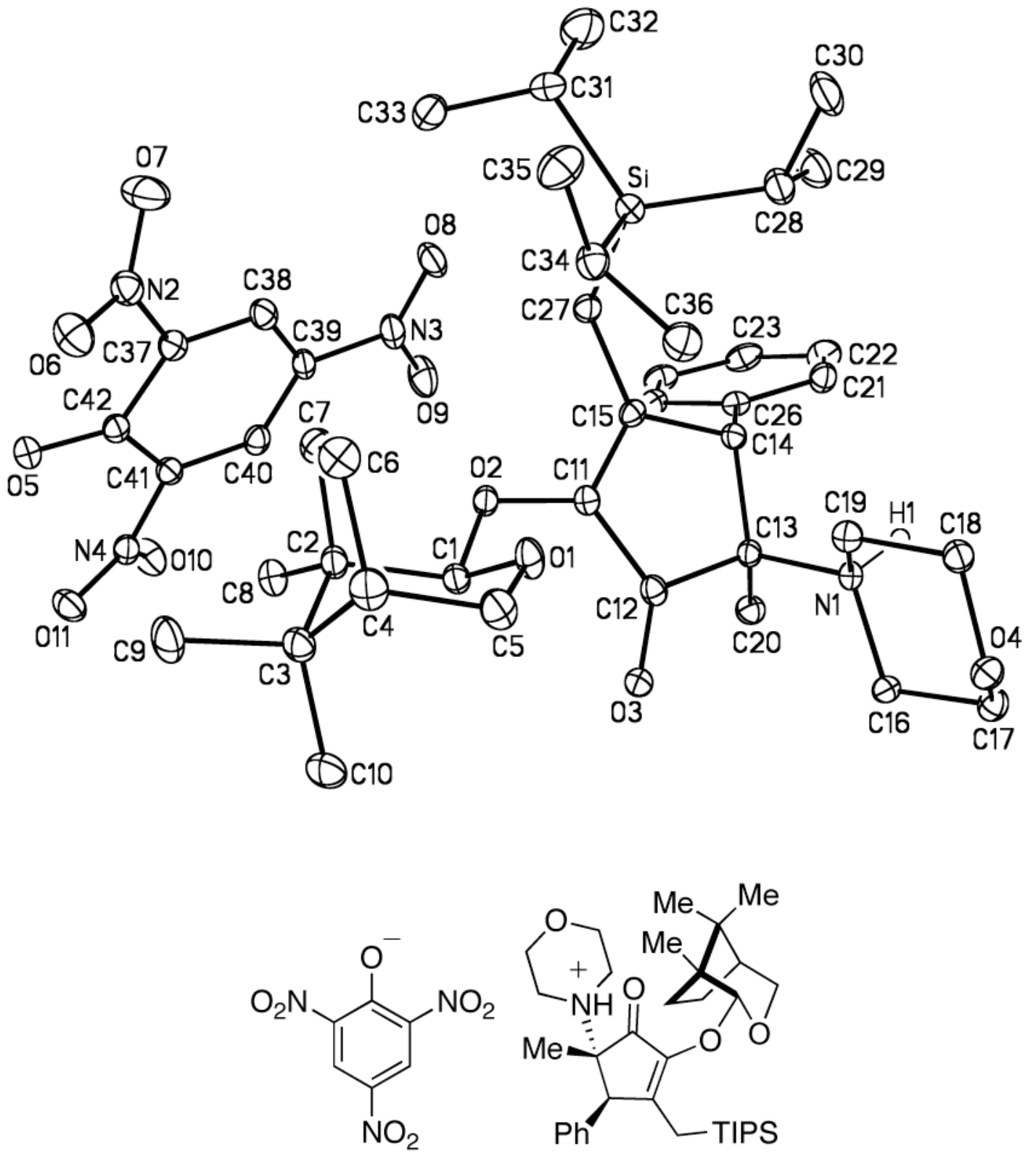

Figure 2.

Molecular diagram of the picrate salt of $\mathbf{2 0}$ with thermal ellipsoids shown at $30 \%$ probability. Quaternary amine hydrogen atom $\mathrm{H} 1$ depicted with arbitrary radius. All other hydrogen atoms omitted for clarity. Orthorhombic; $P 2{ }_{1} 2_{1} 2_{1} ; a=12.583(4), b=16.903(6), c=19.953(7) \AA$; $w R=4.95 \%$; CCDC 639752 . 


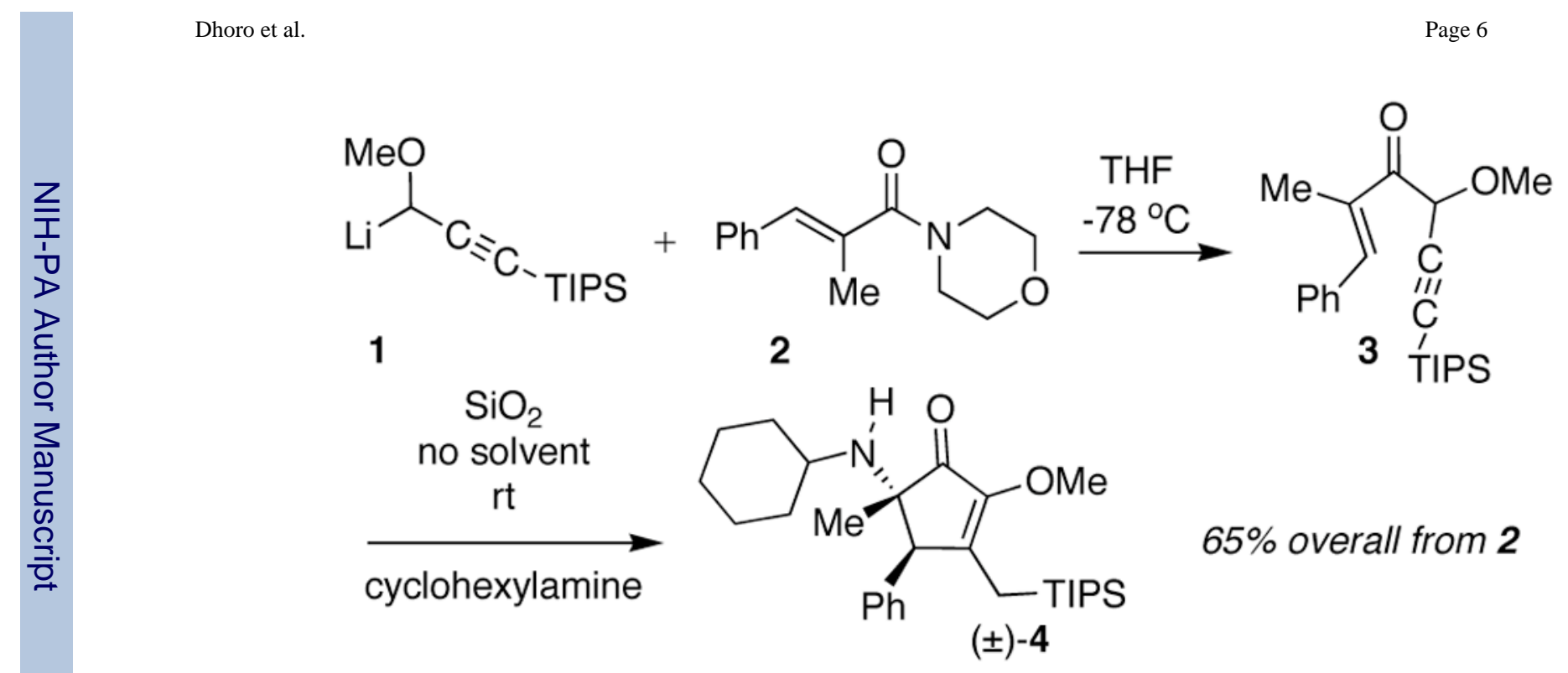

Scheme 1. 
<smiles>CC(=Cc1ccccc1N)C(=O)N1CCOCC1</smiles>

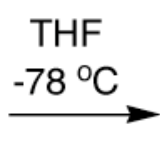

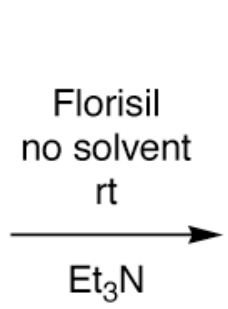

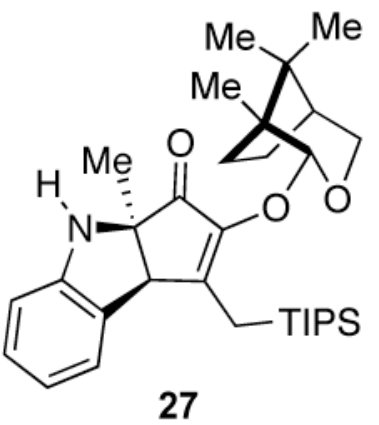

Scheme 2. 
<smiles>C/C(=C\c1ccccc1N)C(=O)N1CCOCC1</smiles><smiles>F[Pb]1CC[13CH]C1</smiles>

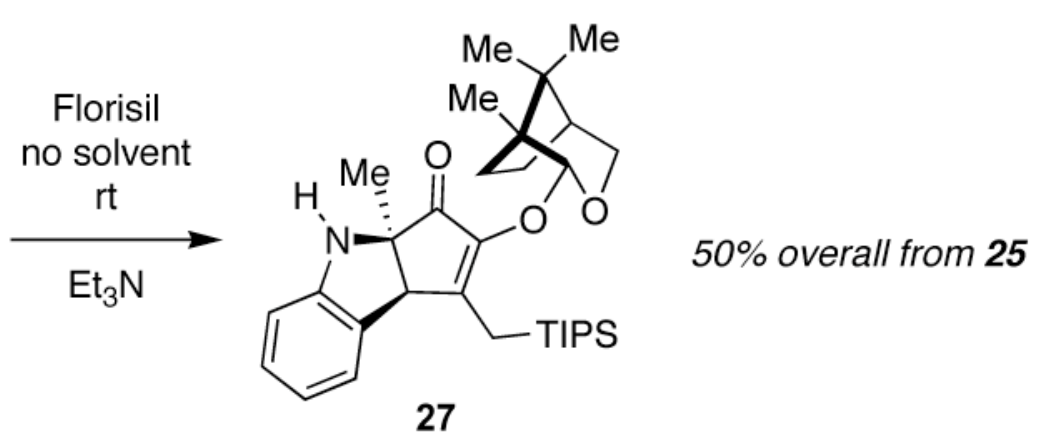

Scheme 3. 


\section{Table 1}

Aminocyclopentenones ${ }^{a}$

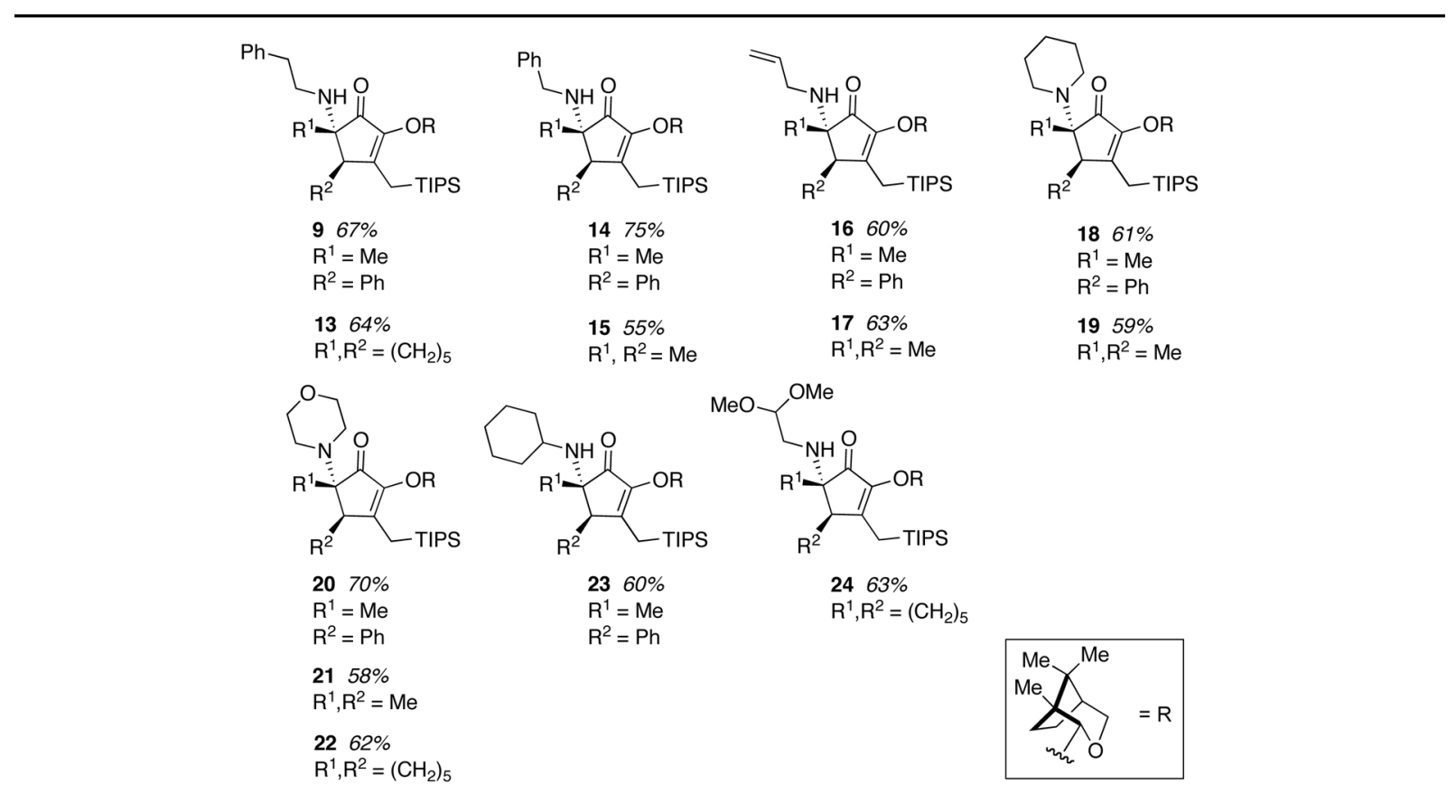

${ }^{a}$ Enones were stirred with activated Florisil ( $c a .6 \mathrm{~g} / \mathrm{mmol}$ ketone) and 10 equiv of amine for 45 min. Yields are for cyclization of the propargyl vinyl ketones. 